\title{
Diagnosis and Reduction of Electricity Consumption Exceedance in Public University Buildings
}

\author{
Olympia Zogou ${ }^{*}, 1$ and Tassos Stamatelos ${ }^{2}$ \\ ${ }^{I}$ Mechanical Engineering Department, University of Thessaly, Greece \\ ${ }^{2}$ Vice-Rector, Infrastructure and Technical Works, University of Thessaly, Greece
}

\begin{abstract}
Higher education costs per graduating student are globally increasing to unsustainable levels, taking into account the worldwide economy problems. Electricity consumption is an essential part of university building operation costs. Thus, many universities struggle to reduce them. To succeed in the reduction of electricity consumption in public buildings, it is essential to detect, identify and classify different kinds of consumption exceedance modes in the electricity consumption time series as early as possible. Intelligent diagnosis and prognosis has already become an important field of interest in engineering. This paper presents a diagnosis methodology that we developed and applied in the University of Thessaly, aiming to find cases of unnecessary high consumption. The methodology is based on the analysis of hourly electricity consumption data from seven university building complexes with separate medium voltage substations. The follow-up measures adopted are also presented, along with the overall effect on the evolution of electricity consumption.
\end{abstract}

Keywords: Buildings, electricity consumption, energy conservation, energy diagnosis.

\section{INTRODUCTION}

Higher education costs per graduate have continuously been increasing internationally since 1950 . Especially in the USA, the annual fees for an undergraduate student in a private university can be as high as $50,000 \$$. The same trend was observed until the end of the first decade of 2000 in public universities in Europe. Greece was no exception to this trend. According to data compiled by the Hellenic Quality Assurance and Accreditation Agency [1], the cost per regular undergraduate for 2009 was estimated to $12,000 €$ in NTUA, whereas it was about 7,500 $€$ in the University of Thessaly.

Of all the challenges being confronted by the public university system in Greece, energy consumption cost is not the least important. On the average, energy consumption expenses amount to $30 \%$ of the total operating costs of our university (which are currently limited to 4.5 million $€$, excluding salaries and students' benefits). For example, total electricity bills amounted to $881 \mathrm{k} €$ in $2011,972 \mathrm{k} €$ in 2012 and reached $1021 \mathrm{k} €$ in 2013, when a new campus in the town of Lamia was added to the University. Various campus facilities contribute to various levels to this figure, according to their energy performance ratings and administration modes applied. It should be mentioned here that the University of Thessaly is currently operating in 5 towns of Thessaly/Central Greece, with more than one campus in Volos and Larissa. The University Administration took seriously into account the significant increasing trend of the annual energy expenses (electricity and natural gas $[2,3]$ )

*Address correspondence to this author at the Mechanical Engineering Department, University of Thessaly, Greece; Tel: +30 24210 74013;

Fax: +30 24210 74085; E-mail: olyz@uth.gr and adopted specific energy conservation measures in 2010, based on suggestions by the Laboratory of Thermodynamics \& Thermal Engines, Mechanical Engineering Department, which systematically monitors and analyzes energy consumption in the buildings of the University of Thessaly, proposes measures for the reduction of energy consumption and assesses their results $[4,5]$.

In this paper, we focus on electricity consumption, which is the major part of energy consumption in our university. Our newest building complex, the School of Medicine in Mezourlo, Larissa, commissioned in 2009, scores C in the A-G energy performance range of categories. Moreover, this building shares certain design and zoning characteristics with the nearby University Hospital (according to the 2003 Commercial Building Energy Consumption Survey, the energy use intensity for hospitals ranks just behind the foodservice sector [6]). On the other hand, most University buildings in Volos are old buildings that have been rehabilitated, with insufficient insulation measures. This fact partly contributes to the high normalized energy consumption levels shown in Fig. (1).

Fig. (2) presents the evolution of electricity consumption in the six University building complexes with medium voltage substations. The School of Medicine campus is located in Larissa, the School of Veterinary Medicine in Karditsa and the remaining building complexes shown in Fig. (1) are located in Volos. The sudden spike in energy consumption that is observed in 2009 (Fig. 2), is due to the fact that 2009 was the first complete year of operation of the new building of the School of Medicine. The building gradually started operation towards the end of 2008, with a small initial consumption seen in Fig. (2) for this year. In 2010, a bundle of measures were adopted to reduce electricity consumption in all building complexes of the 


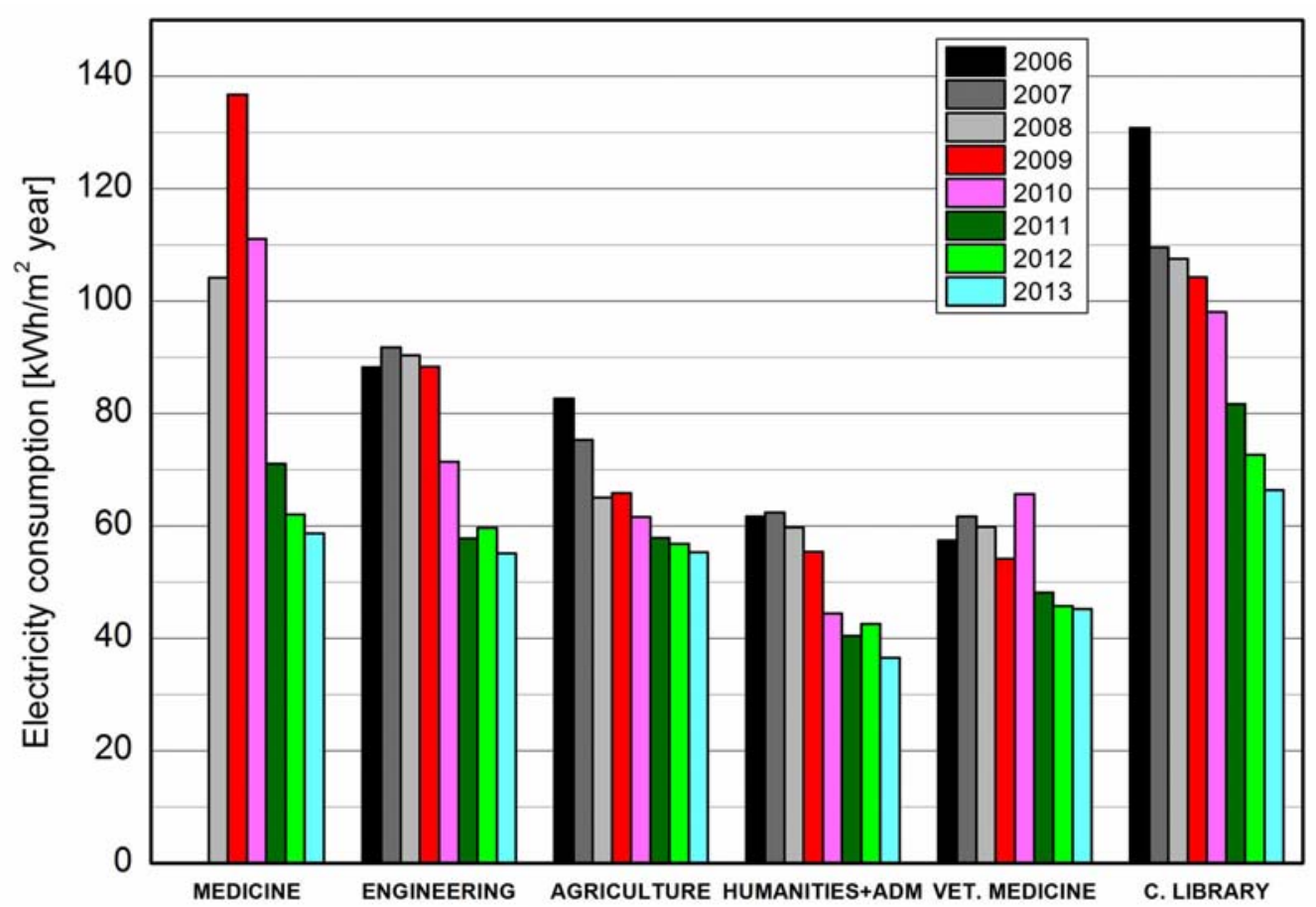

Fig. (1). Evolution of normalized electricity consumption figures in six University building complexes (2006-2013).

University. These administrative and control system measures saved more than $100,000 €$ and 1.2 million $\mathrm{kWh}$ of electricity between 2010-11 and a new reduction of the same level was succeeded between 2011-12. The overall electricity consumption of the University for the specific buildings was reduced by 40 percent between 2009 and 2013 (Fig. 2) [7].
In order to allow better assessment of the improvements, it is useful to take into account the patterns as expressed by the evolution of average monthly Dry Bulb temperatures in Volos, in the period 2009-2013 (Fig. 3). Average winter and summer temperatures are also presented in the same figure.

Obviously, there exists further electricity consumption reduction potential. This is apparent from an inspection of

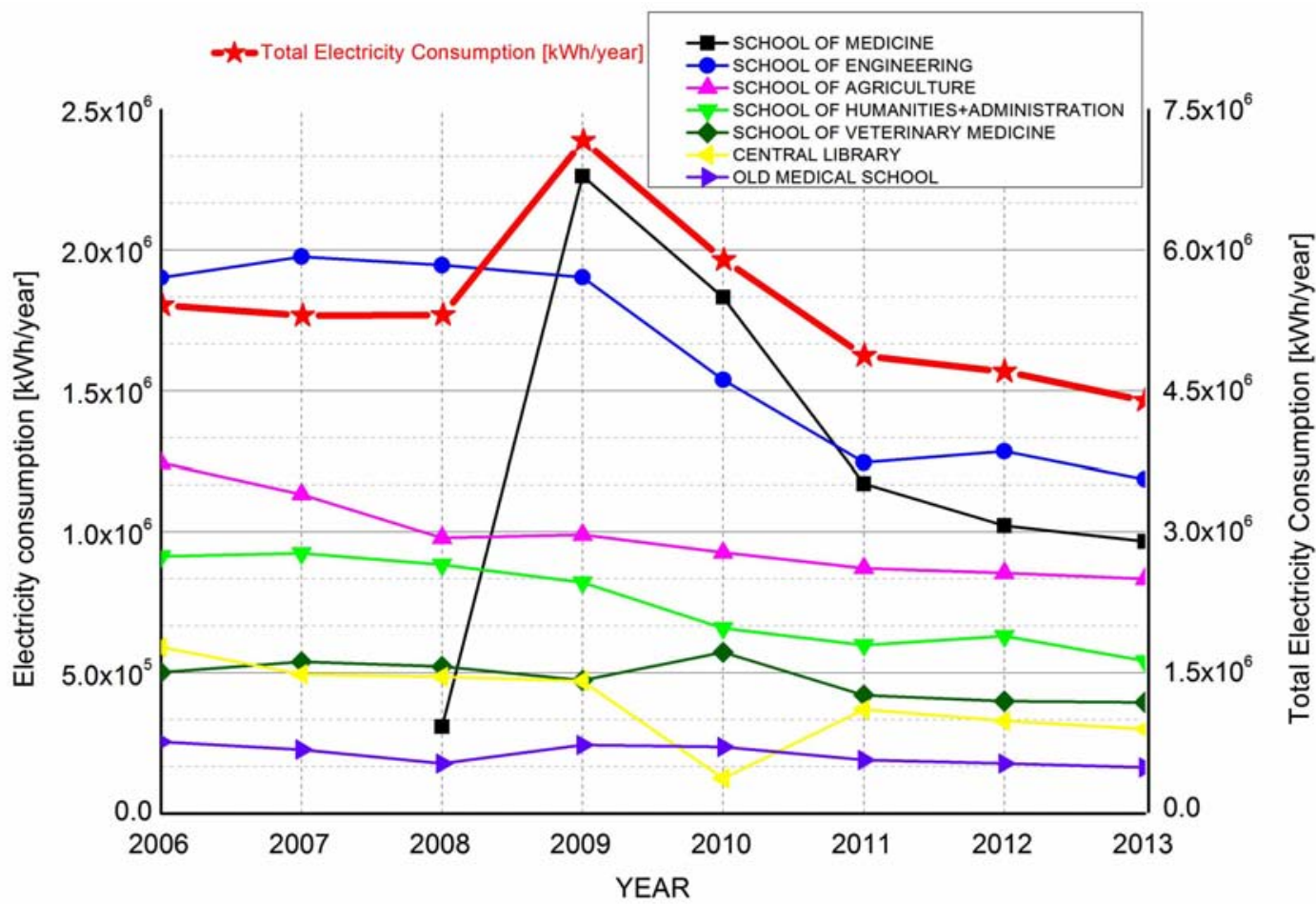

Fig. (2). Evolution of electricity consumption in the main University building complexes in the period 2006-2013. 


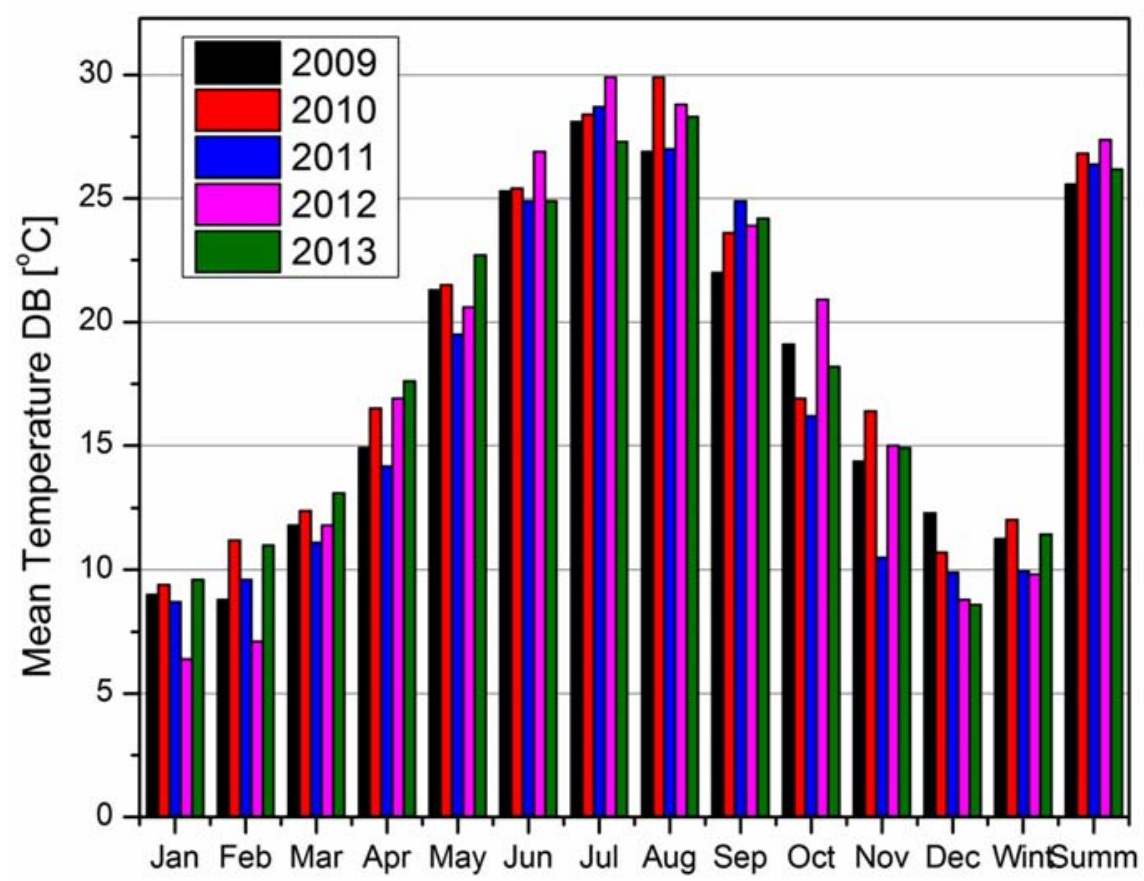

Fig. (3). Average monthly Dry Bulb temperatures in Volos for the period 2009-2013.

the normalized electricity use intensity figures per $\mathrm{m}^{2}$ and year in Fig. (1), and a comparison with internationally accepted figures of primary energy consumption for buildings with acceptable energy performance. Total normalized primary energy consumption must also include natural gas consumption for heating (out of the buildings of Fig. (1), only the central library building uses electricity of heating by means of a VRV heat pump system - the rest are heated by natural gas fired boilers).

In the following section, sweat tempts the formulation of a methodology that exploits the available electricity consumption time series at 15-min intervals, in the diagnosis of electricity consumption exceedance cases. This methodology is applied to focus to specific targets in the continuation of the electricity consumption reduction effort.

The available opportunities for energy consumption reduction are well documented in several guides. For example, the "Advanced Energy Retrofit Guides" [8] lists several opportunities that can lead to savings of more than 30 percent in energy costs of various types of public or commercial buildings (schools, office buildings, hospitals etc). Retrofits are an important part of this practice, providing numerous other benefits as well, ranging from improved equipment longevity to improved levels of thermal comfort and more healthy buildings. The analysis breaks this savings potential into two steps [9]: (i) Fixing what is not working correctly (existing building commissioning, EBX), with improvements in operation and controls for the building envelope, lighting, plug loads, space heating and cooling, ventilation and water heating, and (ii) Upgrading major equipment and components of multiple systems, a fact that may result to complementary benefits. For example, if lighting and HVAC systems are replaced and additional roof insulation is fitted, the HVAC system designer can take into account the reduced cooling load achieved, taking also into account additional small units installed in the meantime, resulting in a smaller cooling system.

Electricity consumption monitoring in medium voltage installations is available from the Public Electricity Corporation (DEH) for 15-min intervals (e-billing system). It includes active and reactive power. This type of information is not yet available for low voltage installations. However, smart electricity meters are currently being installed in University buildings with low voltage supply. In the medium voltage installations that feed more than one buildings, with different type of activity, we have the problem of estimation of allocation of the consumed $\mathrm{kWh}$ between the different buildings. However, the existence of a database with the technical data of the main equipment helps extensively in this direction. In this paper, we present specific examples of how one can differentiate between buildings with a common electricity supply and monitoring, taking the most information possible from the good time discretization available.

In the following sections, examples from the analysis of 15-min monitoring data for the following medium voltage supplies will be presented, to illuminate the diagnosis methodology: School of Medicine, School of Engineering, School of Agriculture, School of Humanities/Central Administration, School of Veterinary Medicine, and Central University Library. Only one of these buildings, namely, the School of Medicine in Larissa, is equipped with a Building Energy Management System (BEMS). This building complex was the first to apply the analysis of hourly electricity consumption monitoring in 2010, with very interesting findings [10]. At that time, this building complex presented the highest electricity consumption per square meter. The analysis helped understanding the significant problems in the schedule of the buildings energy systems. Specific measures were taken, employing the programming 
capabilities of the BEMS that was assigned to authorized University technical personnel to handle, instead of the private contractors previously employed.

Our analysis continued with the School of Engineering campus buildings in Volos, where we spotted important over consumption problems, mainly with unnecessary nocturnal operation of equipment, most of them corrected with remarkable effects on energy conservation in 2011.

This type of analysis was applied to the rest of the buildings fed by medium voltage substations, until the end of 2011, as will be detailed below.

\section{INSPECTION OF NOCTURNAL ELECTRICAL LOADS}

The study of the hourly variation of electric load may readily suggest cases of unnecessary operation of equipment during the night. An example is presented in Fig. (4), where the minimum electric load of the School of Engineering campus buildings was found to be about $100 \mathrm{~kW}$ in the period 1.1.2009 to 10.4.2010 [4]. This minimum load was observed during the neutral periods (no heating or cooling), which are October and April/May.

This minimum electric load was compared to the nocturnal load of the heating or cooling period. The comparison indicated a significant difference that was found to be due to the uninterrupted nocturnal operation of circulating pumps in the boiler room supplying the Mechanical Engineering and the Architecture buildings. The uninterrupted operation was selected because of the lack of a simple control for the progressive shut-down and subsequent start-up of the circulating pumps. The necessary equipment was installed on May 2010 and led to a remarkable reduction of nocturnal loads, which is apparent in Fig. (3). This simple control saved about $20,000 €$ per year.

There exist significant opportunities for further reduction in electricity consumption of the School of Engineering Campus, that can be found by the detailed study of the hourly load variation. Starting from the period from 25.8-9.9 (Fig. 4), which is the beginning of the Academic Year's activity, one can observe the reduction of weekend consumption that is due to the shut-down of the central air conditioning system. However, the early afternoon peaks in active power are increasing in magnitude during 2010, to drop again in 2011. The significant increase in peak loads at the specific campus may be related to the fact that the promulgation of the energy conservation measures in the spring of 2010 led specific faculty members to install small splitunits to their offices and labs, thus trying to bypass the daily schedule of the central air conditioning system.

The minimum winter nocturnal load is observed to decline close to $65 \mathrm{~kW}$ in 1.1.2011. The search is continued to spot further unnecessary consumptions. The nocturnal load comprises night lighting, uninterrupted cooling of server rooms, rooms with deep refrigeration appliances etc. However, night surveillance by infrared cameras has found split units operating during the night, air handling units of auditoriums or laboratories that are left operating unnecessarily during the night. The minimum nocturnal load measured during the neutral period of April 2011 was about $75 \mathrm{~kW}$, thus indicating further opportunities to spot forgotten electric heaters or split units operating during the night.

This is done by an inspection of Fig. (5), where the significant reduction in 2010-11 explained above becomes apparent. However, a comparison of minimum nocturnal

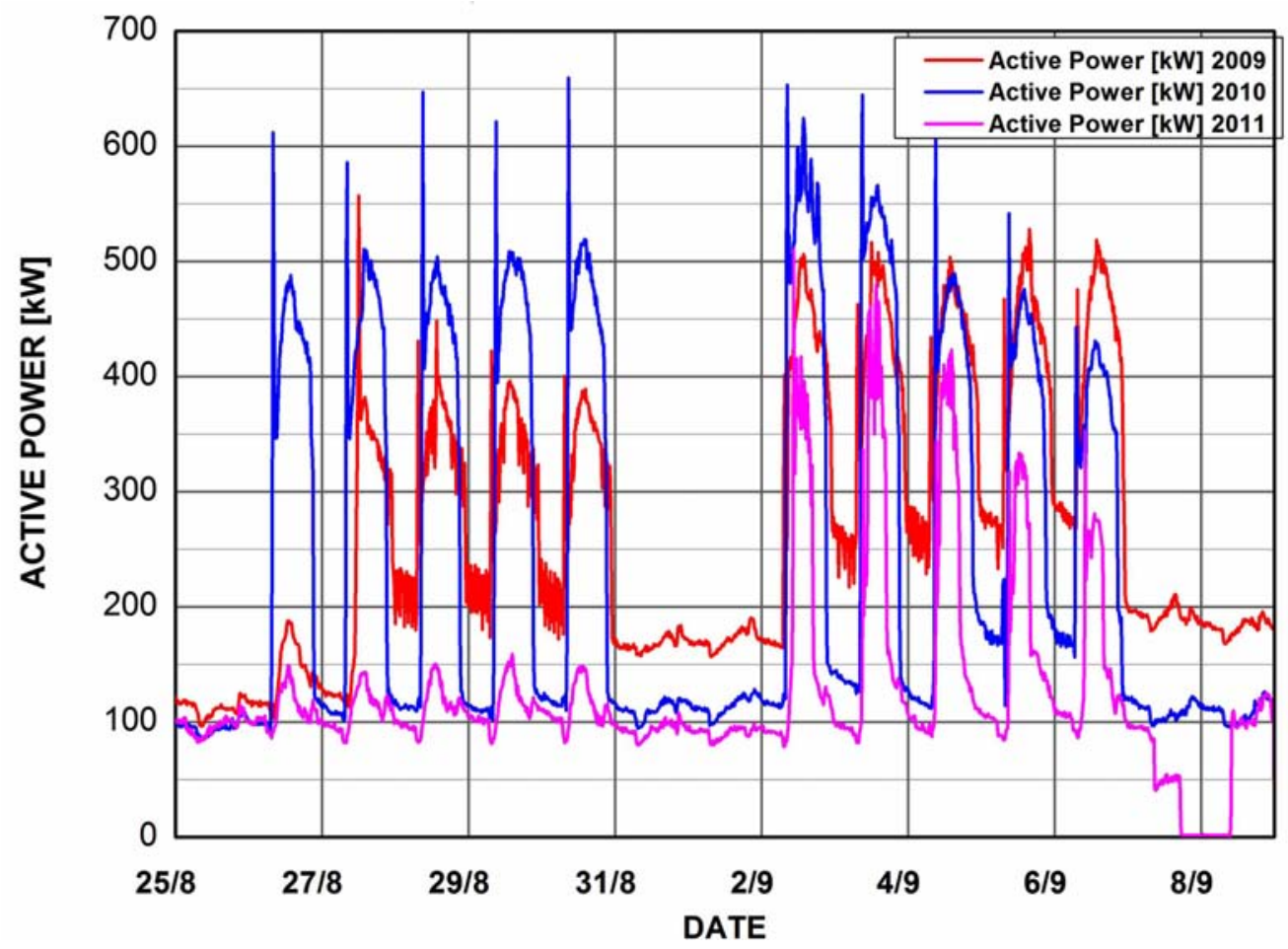

Fig. (4). School of Engineering: Recording of active power for the period 25 August - 9 September, for the years 2009, 2010, 2011: The savings from shut-down of circulating pumps during the night, first applied in May 2010 are apparent for the years $2010-2011$. 


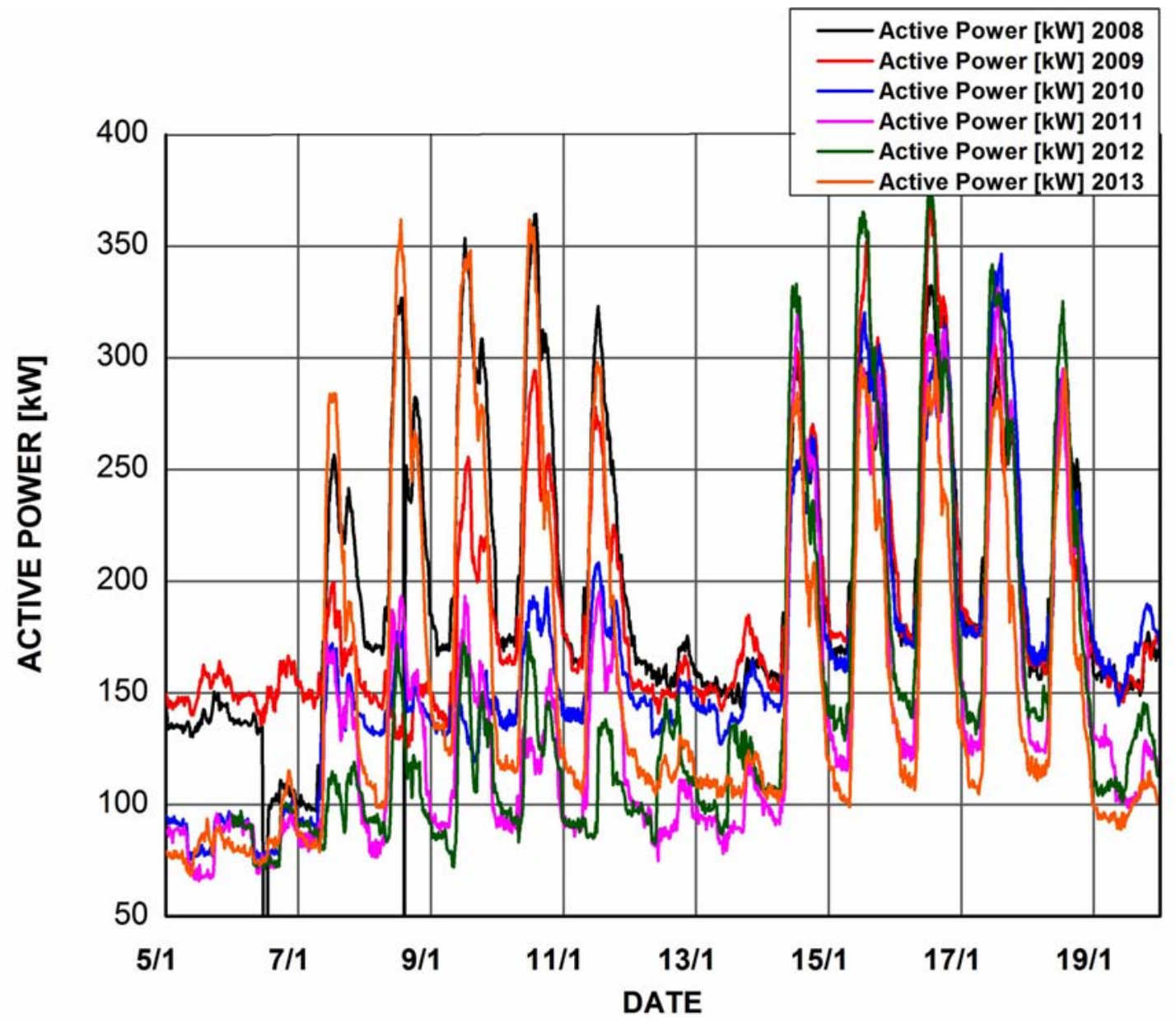

Fig. (5). School of Engineering: Recording of active power for the period 5.1 to 20.1 for the years 2008-2013: High nocturnal loads are apparent in the interval 10-14.1 for 2011, possibly due to electric heaters or split units working unnecessarily.

consumption during the first working days of the year for 2011 and beyond, points to unnecessary consumption starting from 5.1 and especially during the week from 11-15.1, even during the weekend.

The respective situation during the last week of the year is presented in Fig. (6), for the years 2009 to 2012.

According to this figure, the School of Engineering is seen to shut-down most of its activity during the last days of the year, based on a good synchronization of the holidays of its employees, with those of the students. However, it is important to observe the problem with the elevated peak active power during the days before and after Christmas, during 2011 and 2012. It seems that, in response to the energy conservation measures taken in 2010, a number of faculty members installed individual split units in their offices. These devices, possibly along with electric heaters and other equipment seem to be left operating even during Christmas. The same situation is apparent in the nights of working days in the period 11-15 January (Fig. 5). Thus, more strict control of the application of energy conservation rules will be necessary. One measure now in use is the night surveillance of outdoor split units or office windows by infrared cameras.
Fig. (7) presents a comparison of the variation of active electric power recorded in the School of Agriculture, in the period from 1.4 to 5.8, in the years 2009 (before the energy conservation measures) and 2011. The major electric loads in this building complex are posed by the air conditioning chillers. Before 2010, the cooling season started in the middle of May, as it is apparent in the figure. In 2011, the start-up of the chillers is seen to take place in June. There exists further opportunities for improvement in the air conditioning energy conservation. These are related to the shutting down of air supply to specific zones of the building that are not yet occupied by specific activities.

Fig. (8) presents a closer look at the behavior of the building during summer (July), during the years 2009, 2011 and 2012. In 2011, the energy conservation measures taken in 2010 seem to produce favorable results. Also, the air conditioning is seen to shut-down during the weekends. A certain degree of load reduction was succeeded by improving the temperature set points and schedules of air conditioning, resulting in a drop of the peak load from $500 \mathrm{~kW}$ to $400 \mathrm{~kW}$ after 2010. However, in 2012, it is seen that the peaks are reaching again $500 \mathrm{~kW}$, and this is done almost every working day in July - August. The specific building is a refurbished old tobacco warehouse, with a lot of internal spaces without windows. Its air conditioning system is 


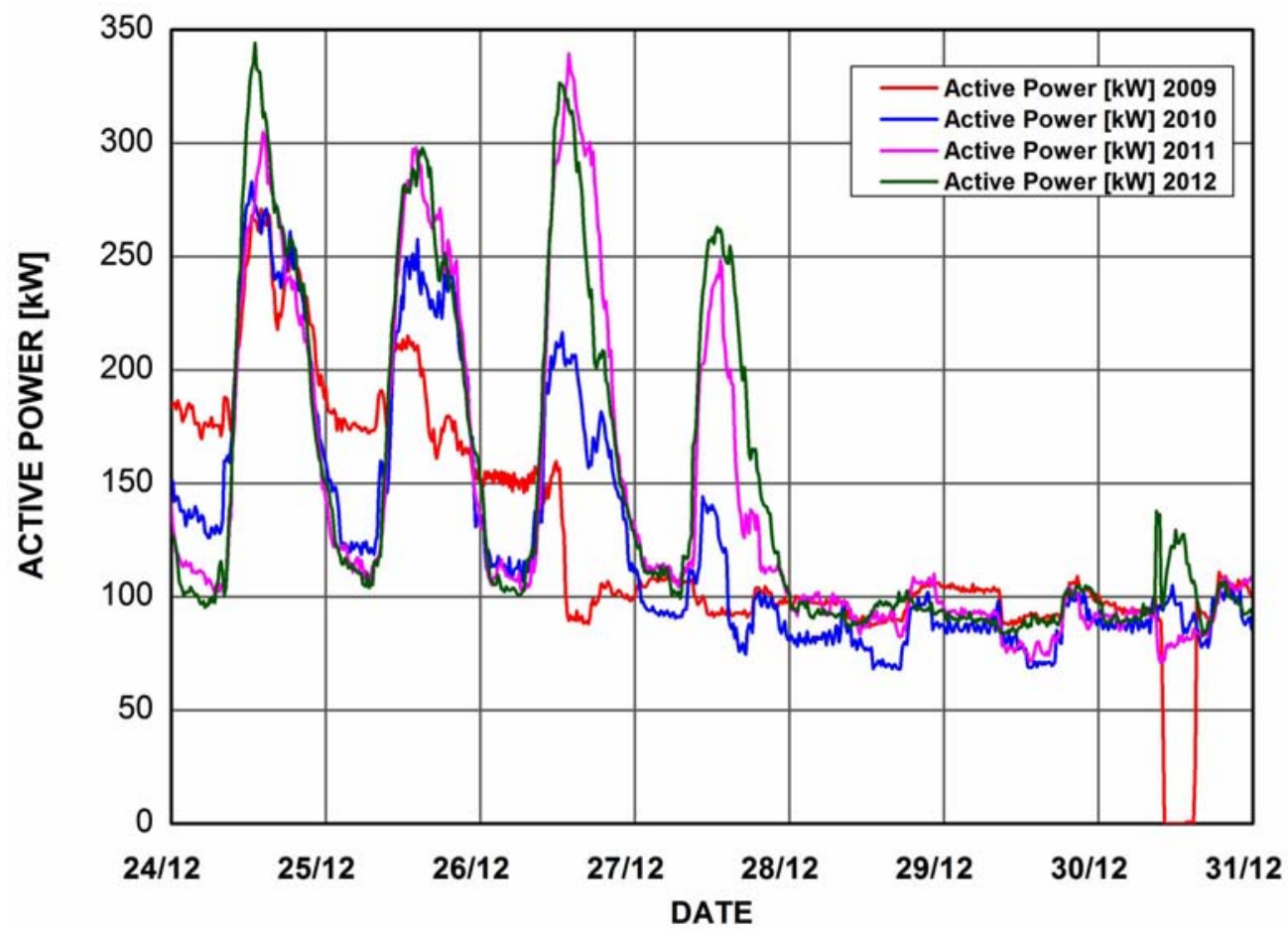

Fig. (6). School of Engineering: Recording of active power for the period 24.12 to 31.12 for the years 2009-2012: Energy conservation due to shut-down during the last week of the year.

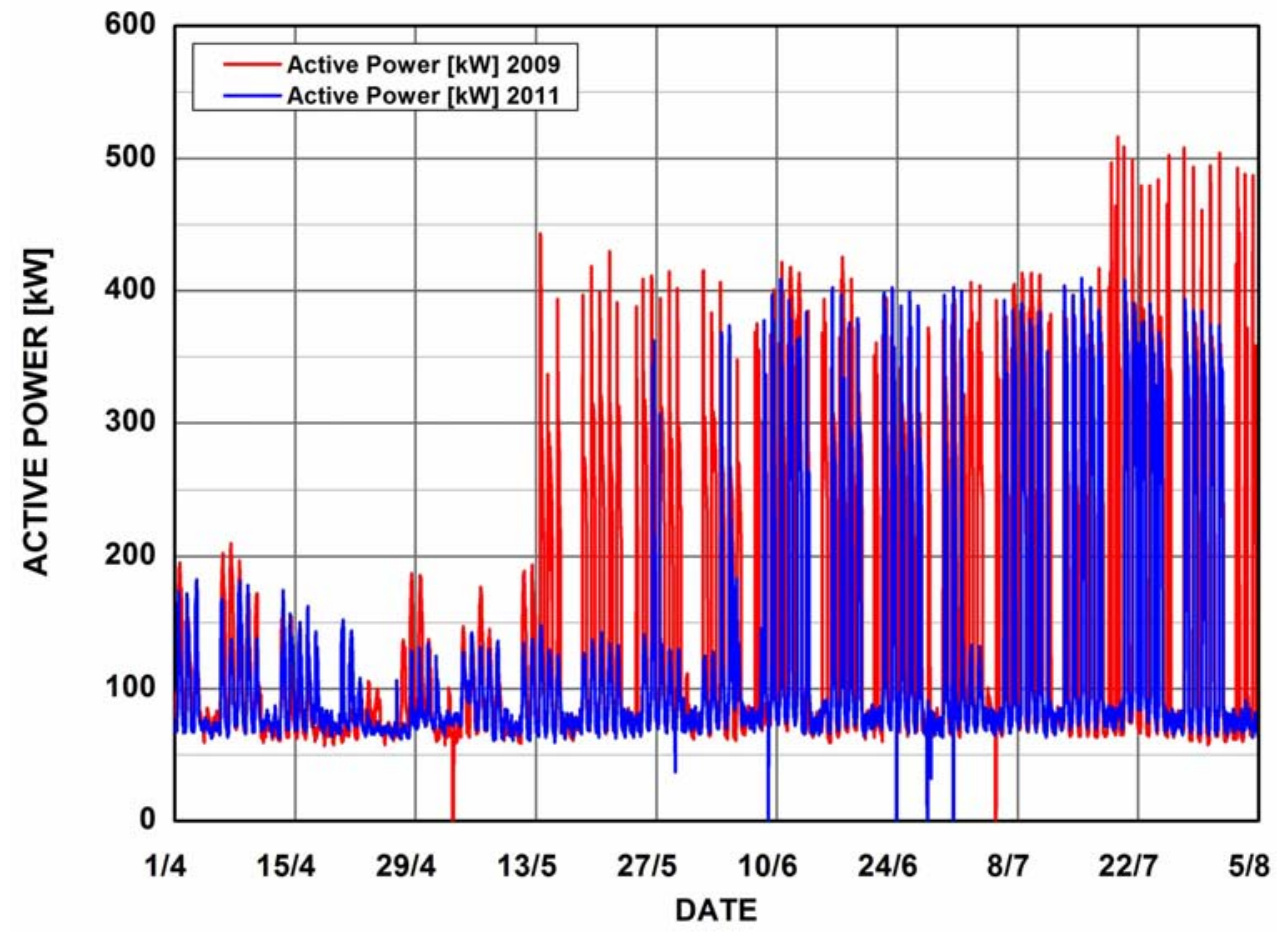

Fig. (7). School of Agriculture: Hourly active power recordings from April to August $(2009,2011)$.

energy consuming, with a lot of duct length outside the building envelope and a large distance from the chillers to the air handling units of the building. The effort to further reduce energy consumption in this building should focus on air conditioning. Specific retrofits will be required to this system that will be timed to coincide with other the installation of new chillers. Only the most simple and costeffective measures are considered in this context.

\section{BUILDINGS EQUIPPED WITH A BEMS}

As already mentioned, the School of Medicine Campus in Mezourlo, Larissa, is the most modern building of our 


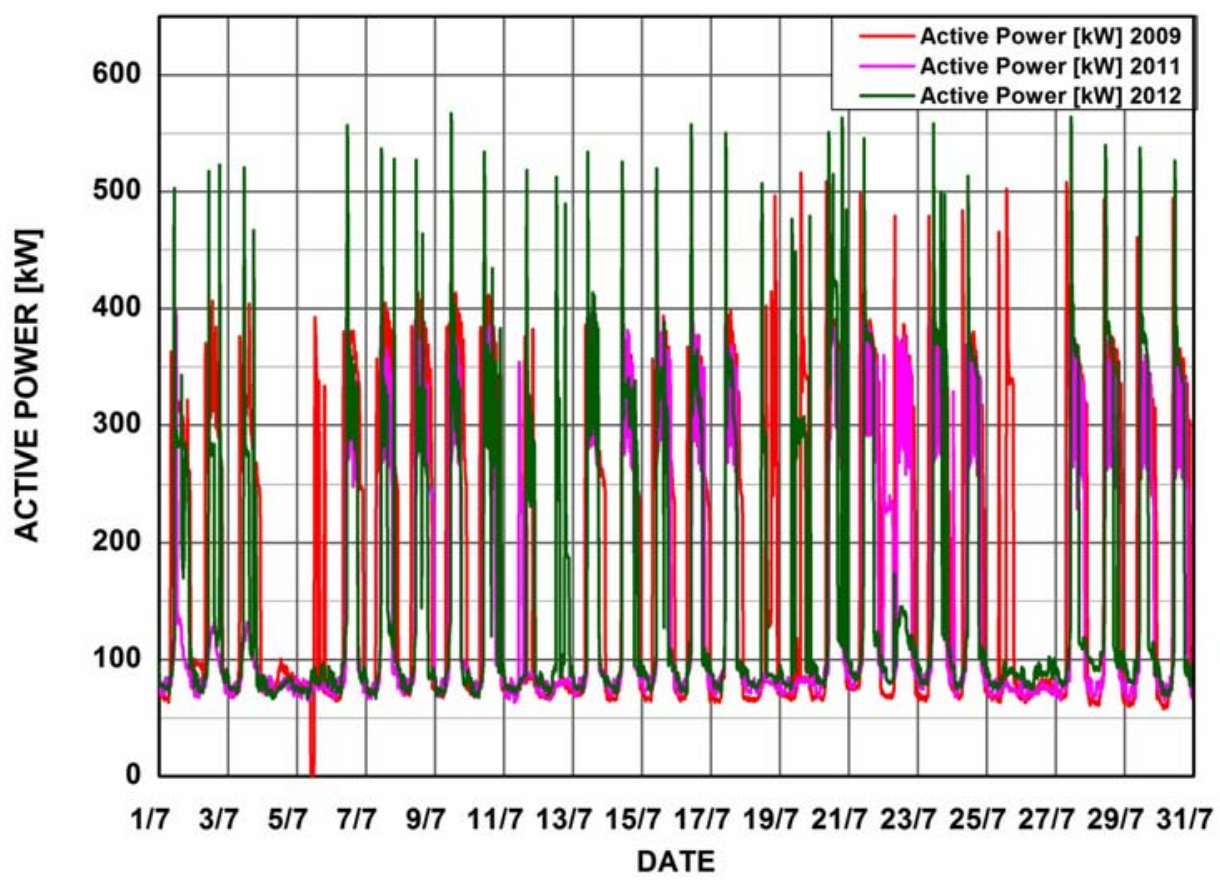

Fig. (8). School of Agriculture: Hourly active power recordings during July (2009, 2011, 2012).

University and the only one equipped with a BEMS. In this building complex, the initially very high energy consumption per square meter has been significantly reduced since 2010 (Fig. 2). The measures, easily adopted through the BEMS, included the shut-down of several zones that were not occupied by personnel, as well as a more conservative operating schedule that will be detailed below. However, despite the progress achieved so far, these buildings continue to present the highest normalized electricity consumption of all University buildings, which is close to $60 \mathrm{kWh} / \mathrm{m}^{2}$ year (Fig. 1). The specific zoning design of HVAC system of this building that sometimes groups in the same zone spaces with different operating schedules is partially responsible for this inconvenience. Obviously, further reduction opportunities continue to exist that will be apparent in the analysis of hourly loads presented below.

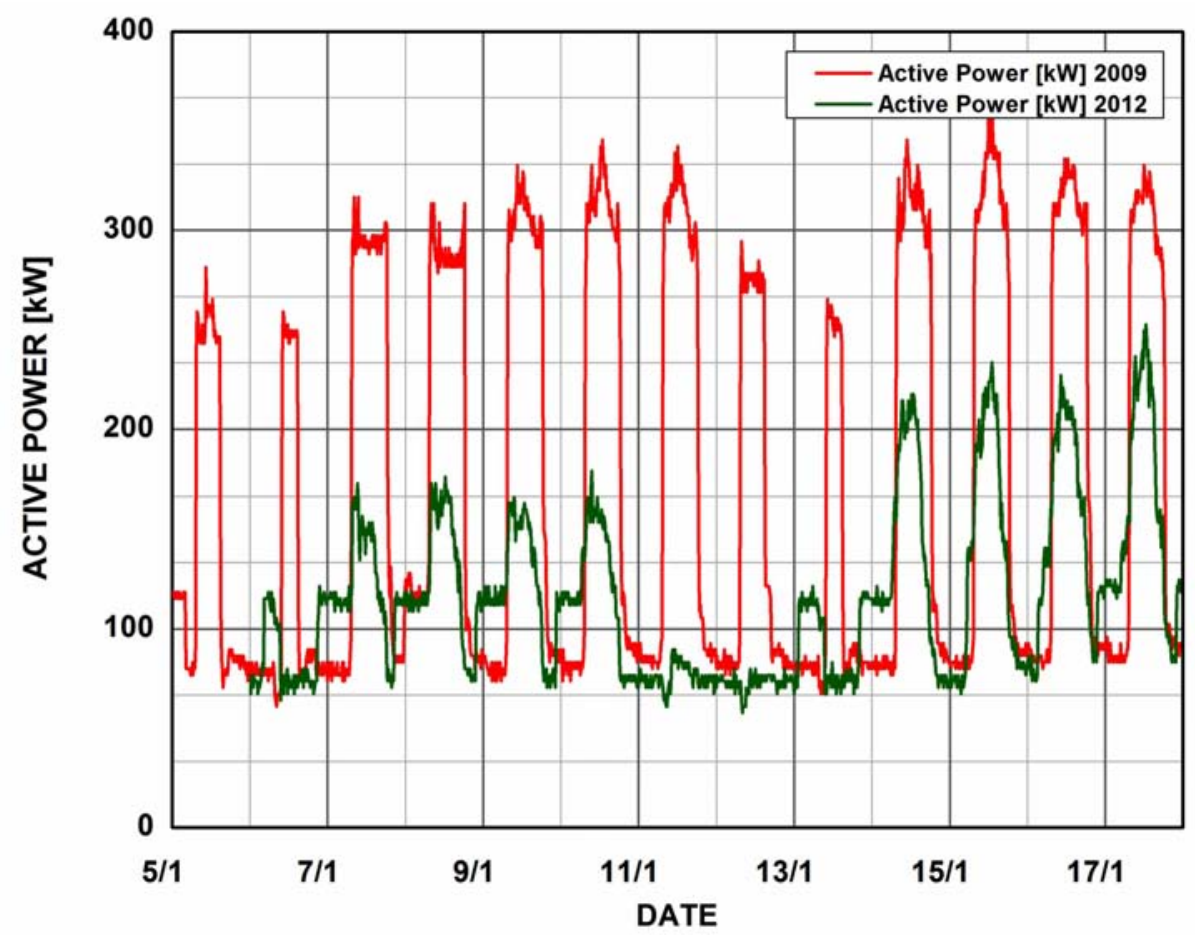

Fig. (9). School of Medicine: Hourly active power recordings for the period 5 - 18 January (2009-2012). 
Fig. (9) presents a comparison of hourly electricity loads in the School of Medicine, during January, for the years 2009 and 2012.

It is evident that the building management by University technical personnel resulted at significant reduction of electricity consumption in 2011. Correct setup of the parameters in the building management system led to the shut-down of significant loads during weekends and holidays, that were left open in 2009. On the other hand, the nocturnal load is observed from $70 \mathrm{~kW}$ in 2009 to $80 \mathrm{~kW}$ in 2011, a fact that is attributed to the installation in a number of laboratories of additional deep refrigerators for the preservation of tissues in 2010 .

Moreover, during 2009, the high daily load peaks extended to four and a half months, namely, June to September and half October. These load peaks sometimes reached $900 \mathrm{~kW}$ (Fig. 10) and were due to the operation of the two large air conditioning chillers of this building complex, with maximum electric power consumed $358 \mathrm{~kW}$ each [10]. The situation is seen to be improved very much in 2012 (Fig. 10). The load peaks now very rarely exceed $500 \mathrm{~kW}$.

A problem persisting in the School of Medicine is that the rule for the synchronization of the holidays of the personnel during the first half of August is not adopted in the specific school. The same is true for the synchronization of the Christmas holidays of the personnel.

For example, in Fig. (11) one can see that although the daily peaks in August are significantly reduced, the air conditioning continues to work even during the biggest summer holiday in Greece which is the $15^{\text {th }}$ of August.
Continuing with the analysis of hourly loads, we present in Fig. (12) the variation of electric load in January 2011, for specific hours of the day. According to this figure, normal operation of this building complex (heating and main loads) starts at 9:00 a.m., whereas it started at 7:00 a.m. in 2009 $[7,10]$. This is a more reasonable schedule since the personnel starts work at about 8:30 - 9:00. Also, a significant load reduction after 14:00 is now observed. The existence of the BEMS in this building allows for effective optimization of schedules and easier fault diagnosis [11].

Similarly, the variation of active power on selected hours of the day in the period from April to August 2011 is presented in Fig. (13). The load peak during summer is observed at 10:00 a.m., probably due to the start-up of the air conditioning. Further, we observe a reduction of the load to the nocturnal levels, after 20:00 from Monday to Friday, whereas the loads are now significantly reduced during the weekends. The nocturnal load is seen to drop in the period from June to August, with its lowest observed value at $60 \mathrm{~kW}$ on 15 August. Thus, there exist further unnecessary consumption points in winter that should be spotted and shut-down.

\section{BUILDINGS WITH MIXED EDUCATIONAL AND ADMINISTRATION USE}

The central University administration building in Volos belongs to a building complex that also comprises the School of Humanities Departments. Thus, in this case we have mixed educational and administration use. As already seen in Figs. (1, 2), this building complex presents the lowest electricity consumption among all University buildings. This

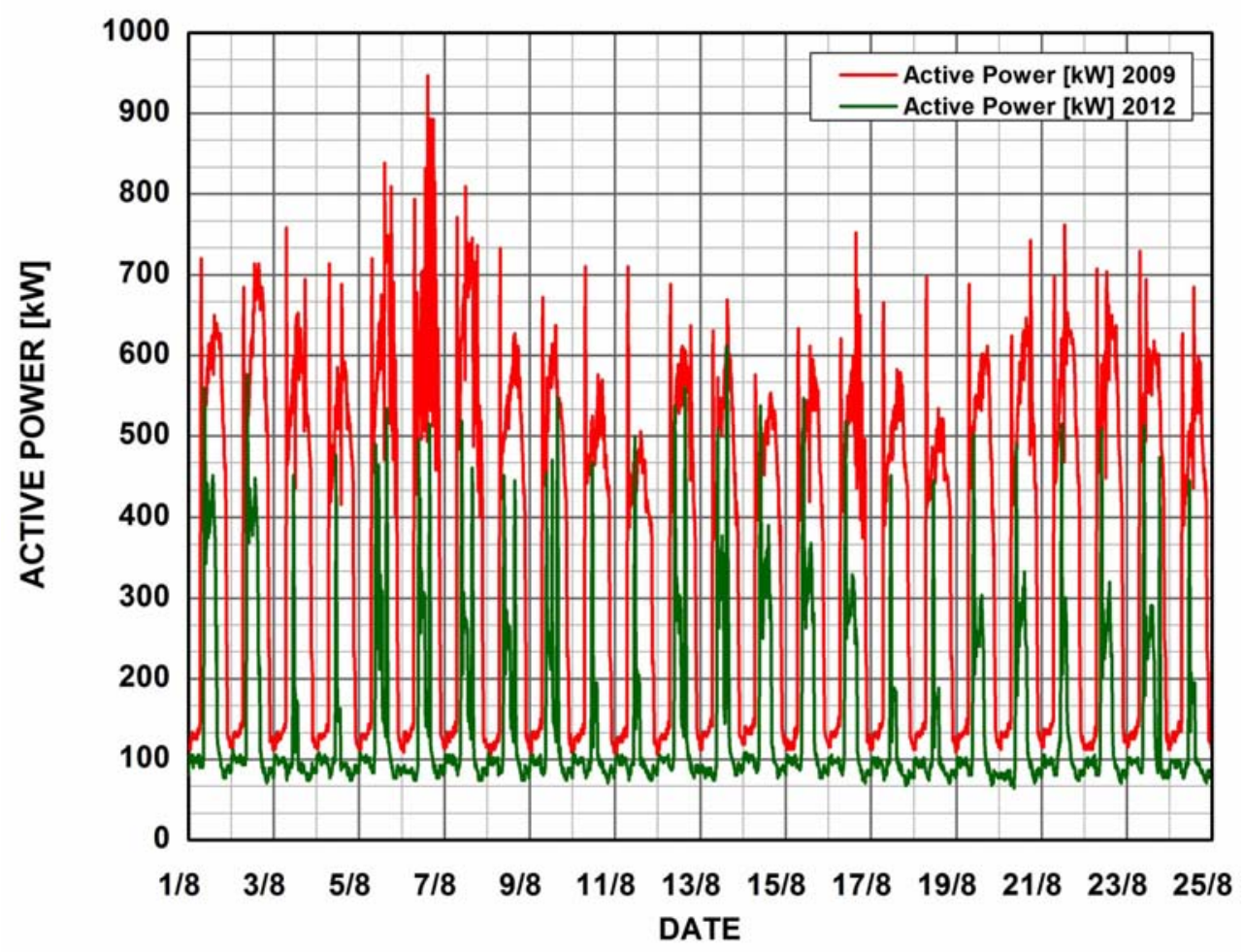

Fig. (10). School of Medicine: Hourly active power recordings for the period 1-25 August. The air-conditioning works uninterrupted during the holiday period of $1-15$ August. 


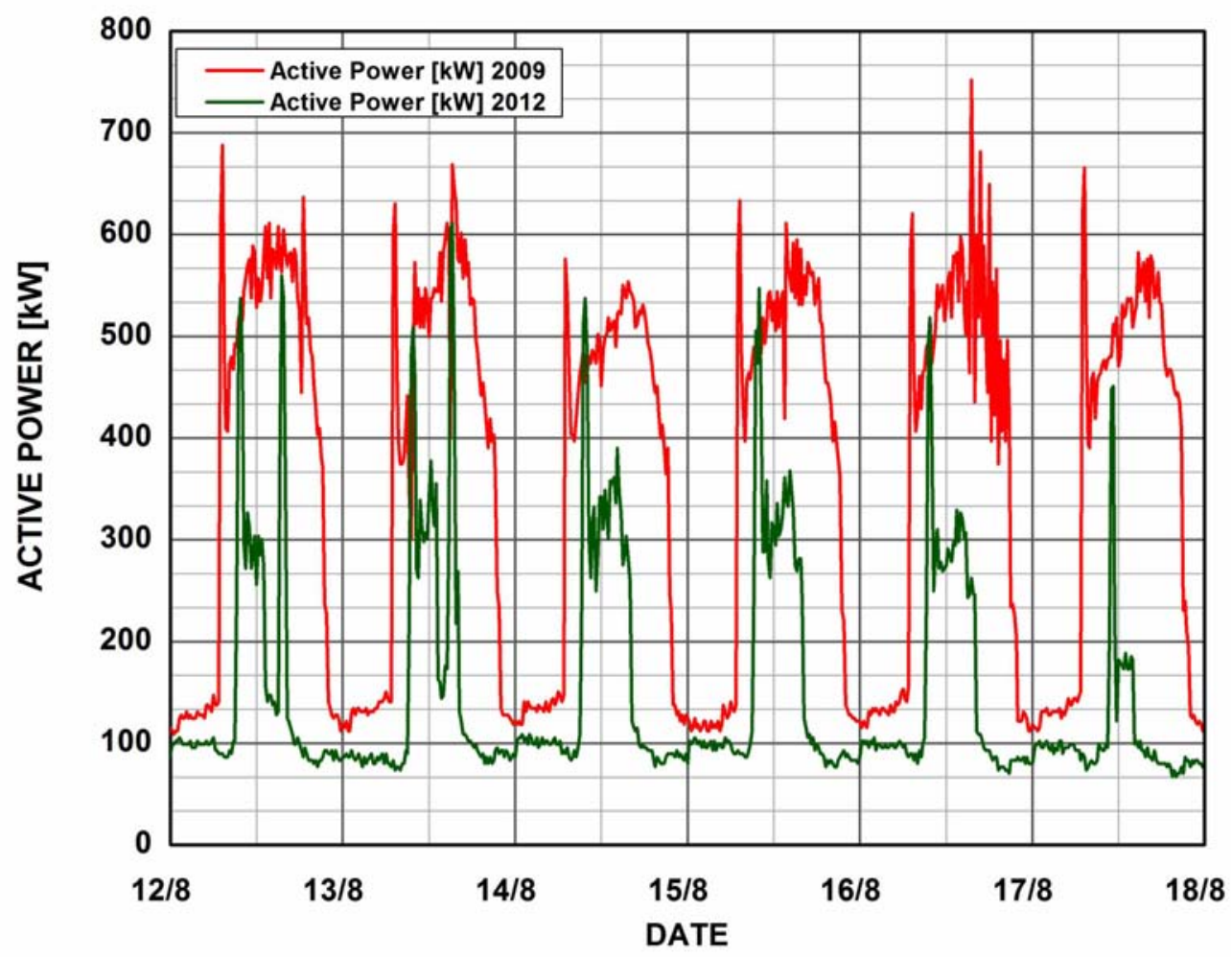

Fig. (11). School of Medicine: Hourly active power recordings for the period 12-18 August (2009 vs 2012). Significant energy conservation from shutting down of specific zones and keeping a more economical schedule for the air conditioning is observed.

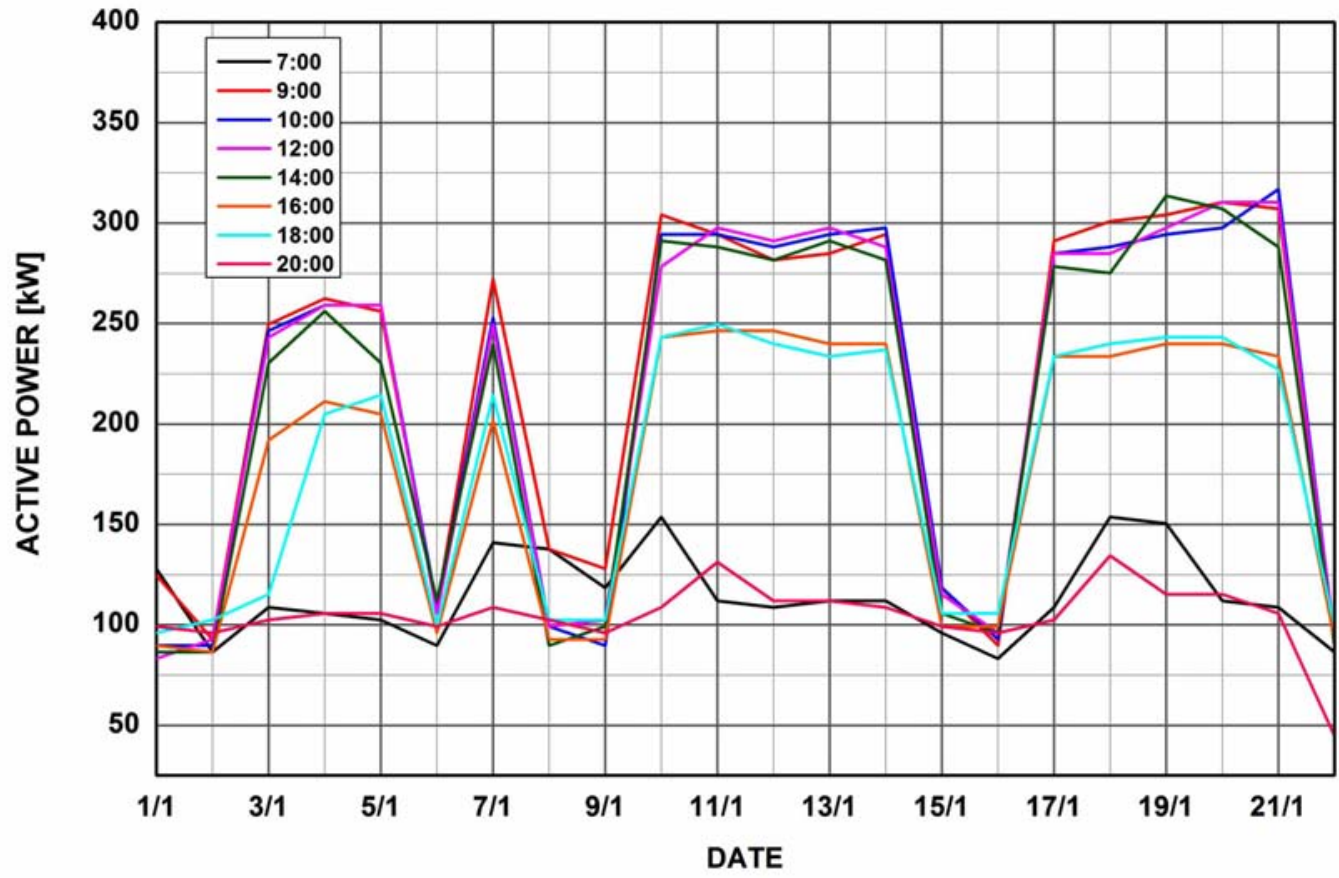

Fig. (12). School of Medicine: Active power profiles for various hours of the day, in the period from 1 to 22.1.2011.

must be attributed to the mixed use of the buildings, as well as to the reduced energy requirements of the few laboratories existing in the School of Humanities.

As presented in Fig. (14), the situation was not well controlled during 2009, where high nocturnal load levels were observed, along with high weekend load levels. The situation improved as of January 2010. However, no significant further improvement was observed during January 2011. An important observation here is that during the first working days of the new year (11-15 January 2011), a lot of equipment (most probably, electric heaters and 


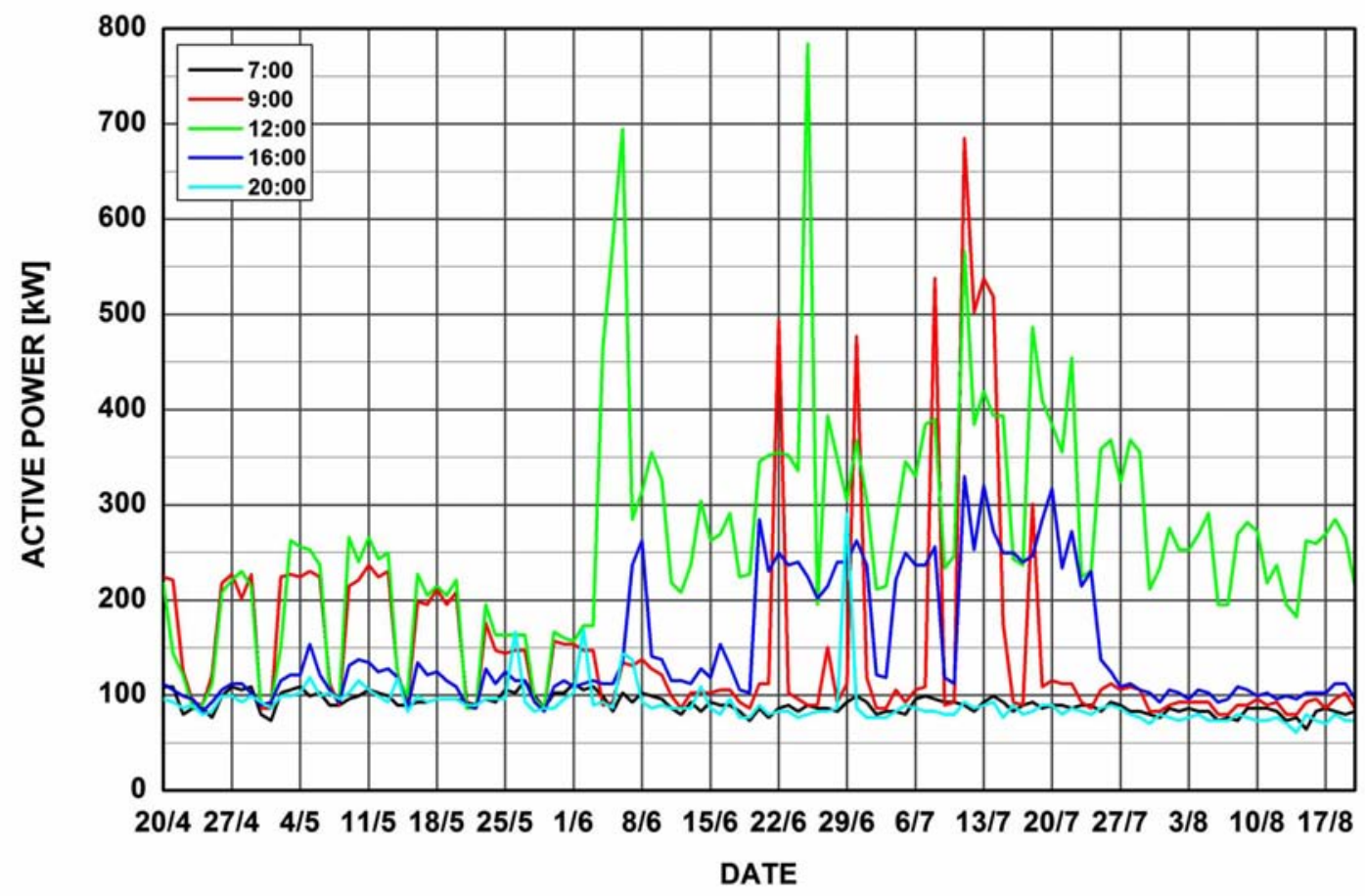

Fig. (13). School of Medicine: Active power profiles for various hours of the day, in the period from 20.4 to 10.9.2011.

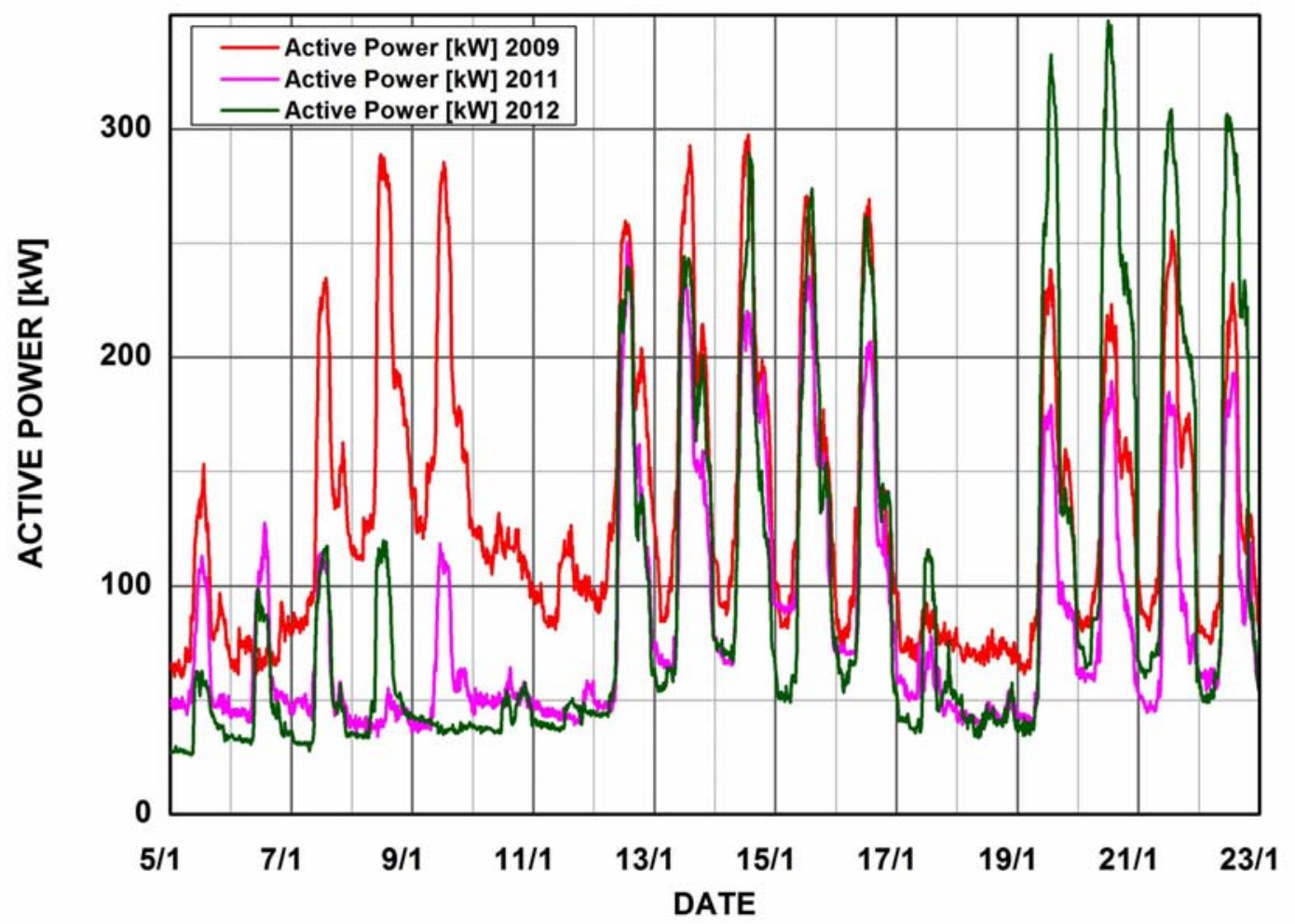

Fig. (14). School of Humanities - University Administration building: Hourly active power recordings for January (2009, 2011, 2012).

radiators) remain operating at night, thus increasing nocturnal load levels by $30 \mathrm{~kW}$. The problem here is more extensive than with that of the previously examined buildings. It needs special attention and penalties should be enforced for those not compliant to the rules.
A comparison of the variation of hourly loads for the months July - August between the years 2009 - 2011 is presented in Fig. (15). The rule for the shut-down of air conditioning and other services is successfully applied for the period of 1-17 August. Successful application of this 


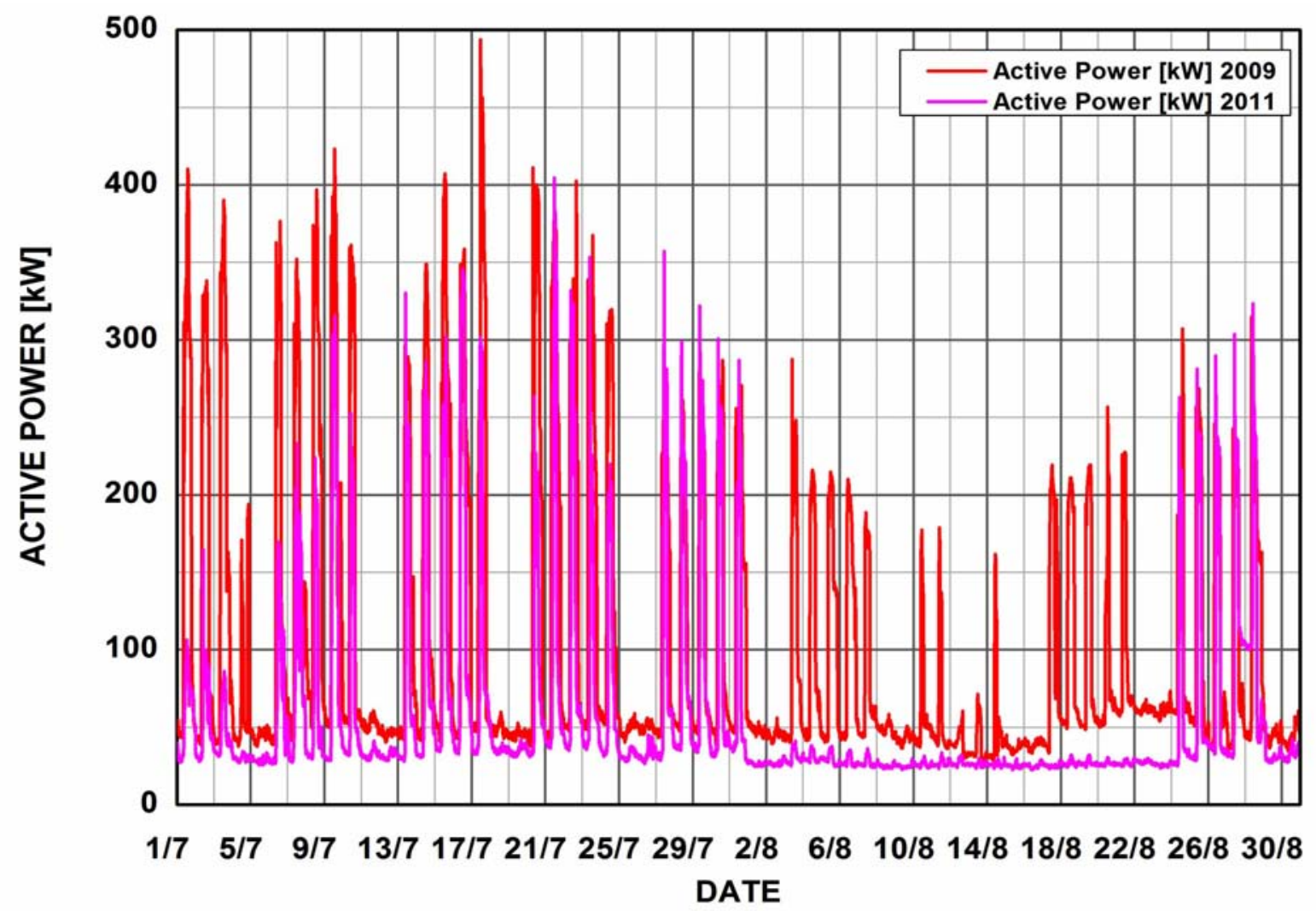

Fig. (15). School of Humanities - University Administration building: Hourly active power recordings for July - August (2009- 2012).

measure led to significant reduction in electricity consumption during 2011. The shut-down of major equipment in the first half of August allows an accurate estimation of the minimum nocturnal load for the specific building complex. This amounts to the order of $23 \mathrm{~kW}$. A comparison with the winter nocturnal loads points to the conclusion that penalties should be enforced to disobedient personnel that leaves equipment to operate during the night.

Based on the experience from 2011, where application of the measures was not so strict in July, we are currently examining an alternative strategy with main focus on the minimization of nocturnal loads, and further interventions to the air conditioning control and schedules that will be based on a detailed study of the variation of hourly load during the day, as well as a better understanding of the coexistence of teaching with administration uses of the building complex.

\section{BUILDINGS WITH HEATING AND COOLING BY ELECTRICITY (VRV HEAT PUMP SYSTEM)}

There exists one building in our University that covers its heating needs by heat pumps (VRV system), thus being independent from the use of natural gas. This is the central University Library in Volos. Thus, the electricity load profile of this building is very different from those previously studied. Maximum of the peak load happens during winter instead of summer.

Fig. (16) presents a yearly profile of the hourly loads of this building. The maximum electrical load peak is observed in January. A comparison between the respective load variations of 2011 and 2012 indicates a significant reduction in energy use from the shut-down of air conditioning during summer holidays.

Although the total electricity consumption in 2011 was increased with respect to 2010, (Fig. 1), the situation is seen to improve in 2012 (a year with higher average air temperature during the year). A careful examination of the daily variation of electric load during December indicates that there exist major variations between different days, as well as between the two years examined. This fact points to inefficient energy management of the building, especially of the air conditioning (heating and cooling) system. It should be mentioned in this context the variations of nocturnal load during the year. The problem needs to be addressed with a detailed study of the situation and possible sources of unnecessary loads. This study would lead to major reduction in energy consumption.

\section{EXPLOITATION OF REACTIVE POWER AND POWER FACTOR RECORDINGS}

Monitoring of the variation of reactive power and power factor in medium voltage substations of university buildings indicates problems from time to time. The problems are corrected with specific interventions to the power factor compensation devices. However, erratic operation of power factor compensation gives us a lot of hints on the operation of various building energy systems.

An example is presented in Fig. (17), with the variation of active and reactive electrical power of the School of 


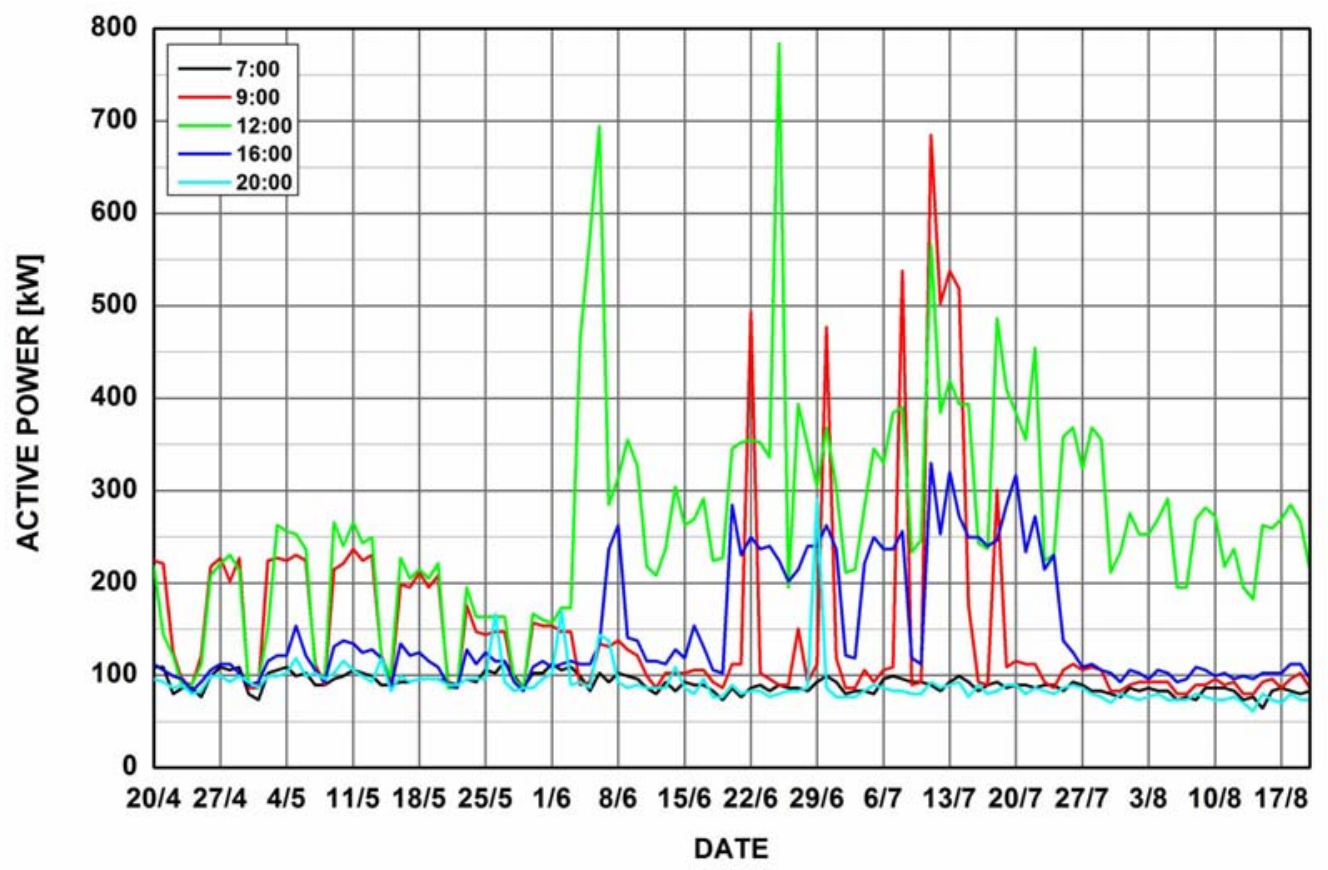

Fig. (16). Central University Library: Hourly active power recordings during $2011-v s-2012$.

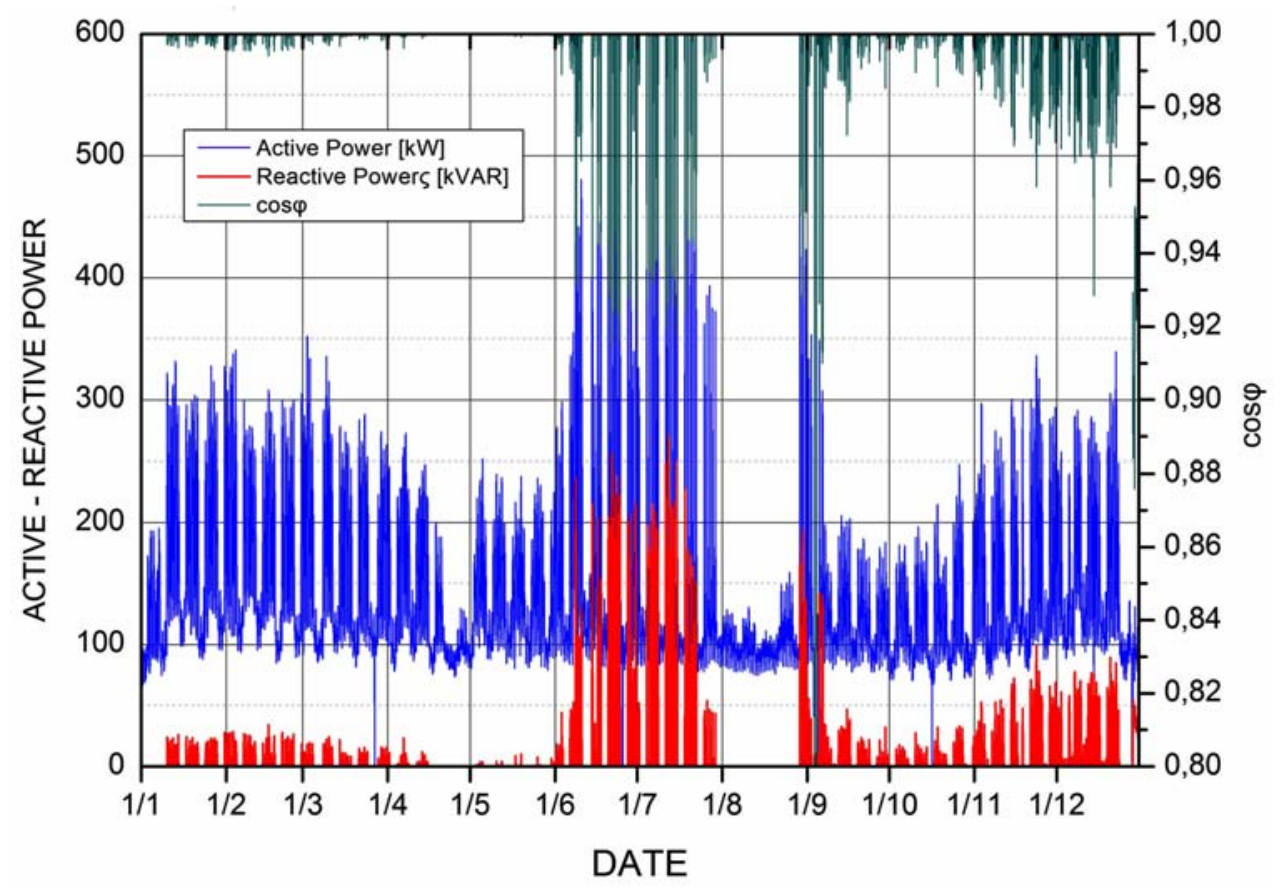

Fig. (17). School of Engineering: Variation of active/ reactive power and power factor, during 2011.

Humanities and Central Administration Building. During 2011, the power factor fell below 0.90 for relatively large periods in winter and summer. It should be mentioned here that the specific building complex uses VRV systems for heating of one of its three buildings. Power factor drop points to the increased operation of compressors, that is, air conditioning systems (Fig. 17, June to the beginning of September, with shut-down in August).

Last but not the least, Miscellaneous Electric Loads (MELs) [12] comprise a growing portion of delivered energy consumption in residential and commercial buildings in Europe and Greece. Based on recent findings from our accounting office, we observe a growth of MELs in our buildings that offset efficiency gains from application of technical improvements and measures in air conditioning or lighting. Miscellaneous electric loads include televisions, video-projectors, personal computers, security systems, servers, etc. that continue to penetrate into buildings, as part of increased service demand for entertainment, computing, and convenience appliances. 
As a next step in the reduction of electricity consumption, we are now planning simple retrofits to specific buildings, that we expect to create significantly more value than the electricity cost savings, by increasing our equipment's life or improving its overall performance (for example, withdrawal of old low performance chillers, fixing and improving insulation of main external ducts and hot or cold water piping, fixing and improving thermal, humidity insulation in roofs etc.).

\section{CONCLUSION}

Systematic monitoring of electricity consumption in major University building complexes that is being applied since 2009, has led to the application of energy conservation measures with remarkable success from 2011 and on.

The total electricity consumption of our University is steadily decreasing since 2010 . However, the big reduction percentages of 2010 and 2011 have not been duplicated. As a consequence of this, our analysis of the electricity consumption profiles needs to become more detailed and exploitation of information present in the hourly electricity load data supplied by the electricity supplier is very important in this direction.

Analysis of the hourly or sub-hourly electricity consumption data allows for a detailed checking of the equipment daily schedules (heating, air conditioning, lighting etc) and their shut-off during weekends and holidays.

The diagnosis by means of analysis of hourly consumption data should be combined with the use of surveillance systems or late night audits for the spotting of unnecessary nocturnal consumption and penalties to the responsible personnel.

The diagnosis of high consumption cases is facilitated by reference to an inventory of technical data of the major electrical equipment installed on each building, which includes: chillers, air-handling units, circulation pumps, VRV heat pumps, and split units.

\section{CONFLICT OF INTEREST}

The authors confirm that this article content has no conflict of interest.

\section{ACKNOWLEDGEMENTS}

The authors wish to thank the members of the buildings' maintenance team of the University of Thessaly, Engineers P. Karinakis, E. Avlogiaris and Mr. P. Apostolakis for their systematic support in the energy conservation campaign.

\section{REFERENCES}

[1] HQAA, Analysis of operation costs in Greek universities, 2011.

[2] Zogou, O. Electricity consumption and spending for five buildings of the University of Thessaly in Volos with medium voltage supply in the period 2006-2009. Laboratory of Thermodynamics \& Thermal Engines, University of Thessaly, 2009.

[3] Zogou, O.; Triantafyllou, N. Electricity consumption and spending for the buildings of the University of Thessaly in Larissa and Karditsa with medium voltage supply in the period 2006-2009. Laboratory of Thermodynamics \& Thermal Engines, University of Thessaly, 2010.

[4] Zogou, O. Proposal of nocturnal electricity consumption and reduction measures, based on the analysis of hourly electric power data from the medium voltage substation of the School of Engineering Campus in the period January 2009-April 2010. Laboratory of Thermodynamics \& Thermal Engines, University of Thessaly, 2010.

[5] Zogou, O. Electricity consumption and tariffs in buildings of the University of Thessaly with medium and low voltage supply in the period 2006-2009, In: Energy Conservation Conference, University of Thessaly, April 2010, Volos, 2010.

[6] EIA, Overview of Commercial Buildings, 2003 Commercial Buildings Energy Consumption Survey, 2006.

[7] Zogou, O. Electricity consumption and spending for major buildings of the University of Thessaly with medium voltage supply in the period 2010-2013. Laboratory of Thermodynamics \& Thermal Engines, Mechanical Engineering Department, University of Thessaly, 2013.

[8] DOE. Advanced energy retrofit guide practical ways to improve energy performance. US. Department of Energy Energy Efficiency \& Renewable Energy Building Technologies Office, 2013

[9] DOE. Advanced Energy Retrofit Guide (AERG) for office buildings, 2011.

[10] Zogou, O. Analysis of hourly electric power data from the medium voltage substation of the School of Medicine Campus in Larissa (Mezourlo) for the period January 2009-April 2010. Laboratory of Thermodynamics \& Thermal Engines, University of Thessaly,2010.

[11] Benjamin Paris, T.T.; Julien, E.; Stéphane, G.; Adama, T.; and Monique, P. On-line monitoring station for energy diagnosis in buildings. In: $11^{\mathrm{TH}}$ International IBPSA Confernce 2009: Glasgow, Scotland July 27-30, 2009.

[12] EIA, Analysis and representation of miscellaneous electric loads in NEMS, 2013. 